\title{
Types of Foot Arch of Adult Bangladeshi Male
}

\author{
M.Tanveer Hossain Parash ${ }^{1, *}$, Humaira Naushaba ${ }^{2}$, Md. Ashfaqur Rahman ${ }^{1}$, Sadia Choudhury Shimmi ${ }^{3}$ \\ ${ }^{1}$ Department of Anatomy, Monno Medical College, Manikganj, Bangladesh \\ ${ }^{2}$ Department of Anatomy, Sir Salimullah Medical College, Dhaka, Bangladesh \\ ${ }^{3}$ Department of Physiology, Delta Medical College, Dhaka, Bangladesh \\ *Corresponding author: parash_cmc@yahoo.com
}

Received June 15, 2013; Revised June 21, 2013; Accepted June 23, 2013

\begin{abstract}
Medial longitudinal arch is the most important arch of the foot from a clinical point of view. The height of the medial longitudinal arch of the foot is commonly thought to be a predisposing factor to injuries. High-arched runners exhibited more bony, ankle and lateral injuries but low-arched runners revealed a higher risk of soft tissue, knee and medial injuries. Again, both high and low-arched people had greater rearfoot eversion excursions than those with normal arch structure. This indicates the importance of measuring and determining the types of the foot arch in Bangldesh as there is no such data. The most reliable and valid way of measurement of the foot arch is the arch height index (AHI), which could be measured by the arch height index measurement system (AHIMS). The AHIMS can be costly to buy or construct for a third world country like Bangladesh Researchers have recently developed an alternative to reduce the cost which involves the use of digital photography to assess the foot arch. The present study was done to measure and categorize the different types of the arch of foot of adult Bangladeshi males using digital photography and caliper. A total number of 110 male students of $3^{\text {rd }}$ and $4^{\text {th }}$ year of Sir Salimullah Medical College, Dhaka were included in the study by convenient sampling after taking approval from the Institutional Ethics Committee. In both sitting and standing position $63 \%$ of the respondents had normal arch, $21 \%$ had high arch and the rest $16 \%$ had low arch. The podiatrists and the plastic surgeons of Bangladesh may use this data to screen, diagnose and manage the pathology accordingly.
\end{abstract}

Keywords: arch of foot, digital photography, anthropometry

\section{Introduction}

The body weight is transmitted to the ground through the foot. The small size of it in relation to the rest of the body places an enormous burden upon it [1]. There are some combinations of abnormal structure and mechanics in the foot that may put an individual at an increased risk for injury. Medial longitudinal arch is the most important arch of the foot from a clinical point of view. The height of the medial longitudinal arch of the foot is commonly thought to be a predisposing factor to injuries. The bony shape, the ligaments of the foot, and the muscular tones all play an important role in supporting the arch [2].

Based on the structure of the medial longitudinal arch, three types of the foot have been proposed: (1) normally aligned or normal foot, (2) low arched or pronated foot, or pes planus, and (3) high arched or supinated foot, or pes cavus $^{2}$. High-arched runners exhibit more bony, ankle and lateral injuries but low-arched runners reveal a higher risk of soft tissue, knee and medial injuries [3]. Again both high-arched and low-arched people had greater rearfoot eversion excursions than those with normal arch structure [4]. So, it is important to have a relatively easy and reliable way to measure and categorize the foot arch. It has implications in research, as well as in the clinical prediction and management of pathology [5].

Several methods have been used to define and categorize arch structure. The most reliable and valid way of the foot arch characterization is the arch height index (AHI), obtained by dividing arch height by truncated foot length [6], which could be measured by the arch height index measurement system (AHIMS) [5].

The AHIMS can be costly to buy or construct for a third world country like Bangladesh . An alternative idea developed recently involved the use of digital photography to assess the arch. Digital photographic techniques potentially offer a highly practical, convenient and cost effective method of assessing arch structure within a clinical or laboratory setting. Such a technique has been shown to demonstrate good to high levels of intra- and inter-tester reliability as well as validity[1].

In Bangladesh there is no data regarding height of the foot arch. The present study is aimed to measure the gross anatomical feature of the foot arch of adult Bangladeshi male. The arch height and truncated foot length were measured by digital photography and foot caliper and AHI was calculated from the foot arch and truncated foot length for valid and reliable data.

\section{Materials and Methods}

The study was cross sectional, descriptive with some analytic components. The study was carried out after approval of the Institutional Ethics Committee of Sir Salimullah Medical College, Dhaka and it was conducted between July 2010 to June 2011 in the Department of Anatomy, Sir Salimullah Medical College, Dhaka. A total 
number of 110 medical students of $3^{\text {rd }}$ and $4^{\text {th }}$ year were chosen by convenient sampling. As the subjects were students of a Government Medical College they were considered to belong to same economical and nutritional status. Again a student of $3^{\text {rd }}$ and $4^{\text {th }}$ year is above 20 years of age and by this age the foot achieves its adult and fixed measurements.

After obtaining written informed consent from the subject, the foot length was measured when the subject was sitting in a relaxed position putting same weight on the both feet after taking off the shoes and the stockings. During measurement the ankle was perpendicular to the foot. The fixed jaw of the caliper was placed on pternion (most backward and prominent posterior point of the heel) and the sliding jaw was fixed on acropodion (most distal tip of the medial malleolous). The caliper was kept parallel to the long axis of the foot. Then, two $4.5 \mathrm{~cm}$ thick wooden blocks (Figure 1: A) were taken. One of them was placed under the heel (in front of the red dotted line) and the other one was placed under the metatarsal heads of right foot leaving the arch unsupported. The left foot was placed $15 \mathrm{~cm}$ left to the right foot on a $4.5 \mathrm{~cm}$ high weight machine (Fig.1: B) so that the distal end of the hallux of the left foot was positioned $5 \mathrm{~cm}$ behind the heel (Figure 1: red dotted line on A) of the right foot. This ensured clear view of the medial aspect of the right foot. A digital camera (Figure 1: C) was positioned on a $4 \mathrm{~cm}$ thick wooden block at a fixed distance of $55 \mathrm{~cm}$ from the medial border of the right foot and $10 \mathrm{~cm}$ forward to of the back of the heel. A small mark was made on the first metatarsal head to enable the identification of this landmark in the photos. Then the photographs were taken with fixed light and fixed focus on the foot with a fixed zoom [1].

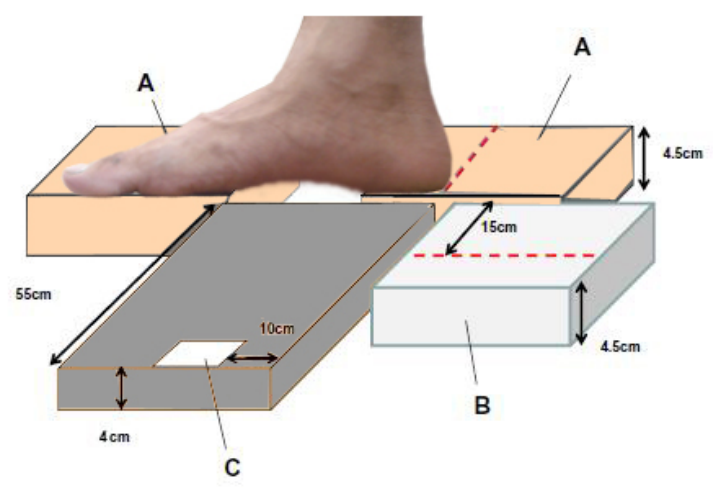

Figure 1. Diagrammatic representation of set up for photographic measurement [1]

All photographs were then transferred to the computer. No enhancements or modifications were made to any of the digital images. The measurements of arch height and truncated foot length $\mathrm{s}$ were taken using the program Adobe Photoshop 7.0. The foot length was measured by digitizing points at the pternion and the acropodion (Figure 2). The total foot length was then halved to determine $50 \%$ of the total length. A vertical line was then drawn at the half of the foot perpendicular from the supporting surface to the dorsum of the foot. The arch height is determined by digitizing co-ordinates at the top and bottom of this line. The truncated foot length was measured by digitizing points at the pternion and the head of the first metatarsal bone (Figure 2).

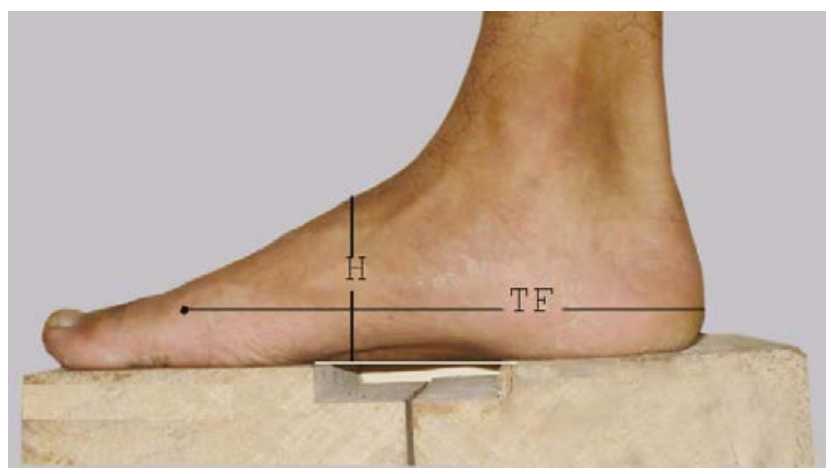

Figure 2. Photographic measurements of arch height $(\mathrm{H})$ and truncated foot length (TFL)

The measured photographic values were multiplied by the corresponding conversion factor to estimate the actual value. Conversion factor for foot length was calculated by dividing the foot length measured by foot caliper with the photographic foot length.

\section{Conversion factor for foot length $=$ \\ Measured foot length by direct method \\ Measured foot length by photographic method}

This conversion factor was used to estimate the actual value from the photographic measurements [7].

The AHI was calculated by dividing arch height with truncated foot length. The whole procedure was repeated for standing condition putting same weight on the both feet. According to the AHI three types of foot were determined [5]:

1. Normal foot $(<\mathrm{AHI}+\mathrm{SD} \times 1.5 \sim>\mathrm{AHI}-\mathrm{SD} \times 1.5)$

2. Low arched foot $(\leq \mathrm{AHI}-\mathrm{SD} \times 1.5)$

3. High arched foot $(\geq \mathrm{AHI}+\mathrm{SD} \times 1.5)$

The data were analyzed with the help of SPSS version 16.0 program keeping in view the objective of the study.

\section{Results}

Table 1. Arch Height, Truncated Foot Length and Arch Height Index of Right Foot in Sitting and Standing Position with Difference and Level of Significance $(\mathbf{n}=110)$

\begin{tabular}{|c|c|c|c|c|c|c|}
\hline Variables & \multicolumn{2}{|c|}{ Measurement } & \multicolumn{2}{c}{$\begin{array}{c}\text { Difference in sitting and standing } \\
\text { position }\end{array}$} \\
\hline & Sitting position(10\%WB) & \multicolumn{2}{|c|}{ Standing position (50\%WB) } & Proportion & p \\
\hline & Mean & $\pm \mathrm{SD}$ & Mean & $5.60 \mathrm{~cm}$ & $0.44 \mathrm{~cm}$ & 0.80 \\
\hline Arch height & $7.00 \mathrm{~cm}$ & $0.55 \mathrm{~cm}$ & $18.77 \mathrm{~cm}$ & $1.07 \mathrm{~cm}$ & $0.000^{* *}$ \\
\hline Truncated foot length & $18.07 \mathrm{~cm}$ & $1.03 \mathrm{~cm}$ & 0.299 & 0.024 & $0.000^{* *}$ \\
\hline Arch height index & 0.388 & 0.032 & 0.77 & $0.000^{* *}$ \\
\hline
\end{tabular}

$* *=$ significant at $5 \%$ level of significance 
The mean $( \pm$ SD) of arch height, truncated foot length and AHI of the right foot of 110 males of 20-25 years in sitting and standing positions with difference and level of significance are summarized in Table 1 . The values of arch height, truncated foot length and AHI ranged from $6.04 \mathrm{~cm}$ to $8.78 \mathrm{~cm}, 15.94 \mathrm{~cm}$ to $20.49 \mathrm{~cm}$ and $0.321 \mathrm{~cm}$ to $0.485 \mathrm{~cm}$ respectively in sitting position and $4.83 \mathrm{~cm}$ to $7.03 \mathrm{~cm}, 16.57 \mathrm{~cm}$ to $21.28 \mathrm{~cm}$ and 0.247 to 0.373 respectively in standing position.

AHI of at least 0.436 and 0.388 were needed for inclusion in the high-arched group, and less than or equal to 0.340 and 0.262 for inclusion in the low-arched group respectively in sitting and standing positions. These values fell at or outside 1.5 standard deviations of the mean AHI measurement of 0.388 (SD $=0.032$ ) and 0.299 $(\mathrm{SD}=0.024)$ respectively in sitting and standing positions based on a previously collected sample of 110 right feet.

The mean arch height, truncated foot length and arch height index changed significantly $(p=0.000)$ in standing from sitting position. However there was no significant $(p=0.963)$ change in types of arches in these positions (Table 2).

Table 2. Types of Arch of the Right foot in Sitting and Standing Position with Test of Reliability and Level of Significance $(n=110)$

\begin{tabular}{|c|c|c|c|c|}
\hline \multirow{2}{*}{$\begin{array}{c}\text { Type of } \\
\text { arch }\end{array}$} & $\begin{array}{c}\text { Sitting } \\
\text { position } \\
(10 \% W B)\end{array}$ & \multirow{2}{*}{$\begin{array}{c}\text { Standing } \\
\text { position } \\
\end{array}$} & $\begin{array}{c}\text { Tukey's } \\
\text { test }\end{array}$ & $\mathrm{p}$ \\
\hline Low & 18 & 17 & \multirow{2}{*}{0.002} & \multirow{2}{*}{$0.963^{\text {ns }}$} \\
\hline Normal & 69 & 70 & & \\
\hline High & 23 & 24 & & Reliability test \\
\hline
\end{tabular}

ns= not significant at $5 \%$ level of significance

In both sitting and standing position $63 \%$ of the respondents had normal arch, $21 \%$ had high arch and the rest $16 \%$ had low arch (Figure 3 ).

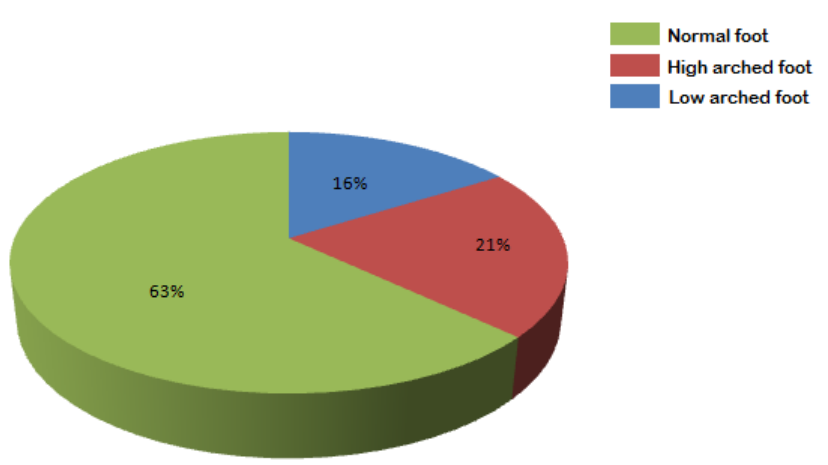

Figure 3. Pie chart showing distribution of arch of foot in adult Bangladeshi male $(n=110)$

\section{Discussion}

The mean arch height of right foot of the subject in the present study was lower than that of the American [1,8], Hong Kong, Chinese [9] and Iranian [10] adult male.
There are no similar data available regarding frequency of distribution of the different foot arches. The results did not resemble with another study where frequency of normal arched foot and high-arched foot were low and frequency of low-arched foot was high to that of the present study [11]. However in both the studies normal arched foot was higher in comparison to the other foot arches.

There are no available studies on these variables of population having similar nutritional status as the present study. Along with this, racial and genetic variation may play an important role compounding to the dissimilarity.

\section{Conclusion}

From the study it can be assumed that the majority of the adult Bangladeshi males had normal arched foot. Further studies on larger populations and different sex and ethnicity may be done to establish a complete data of distribution of different types of foot arch of Bangladeshi population.

\section{References}

[1] Pohl, M.B., Farr, L. A composition of foot arch measurement reliability using both digital photography and caliper method. Journal of Foot and Ankle Reearch, 3(14).6, Jul 2010.

[2] Chang, Y.W., Hung, W., Wu, H.W., Chiu, Y.C., Hsu, H.C. Measurements of foot arch in standing, level walking, vertical jump and sprint start. International Journal of Sport and Exercise Science, 2(2), 35-42, Jun 2010.

[3] Wlliams, D.S., McClay, I.S., Hamill, J., Buchanan, T.S. Lower extremity kinematic and kinetic differences in runners with high and low arches. Journal of Applied Biomechanics, 17, 153-63, 2001.

[4] Kernozek, T.W., Ricard, M.D. Foot placement angle and arch type: Effect on rearfoot motion. Archives of Physical Medicine and Rehabilitation, 71(12), 988-91, 1990.

[5] Xiong, S., Goonetilleke, R.S., Witana, C.P., Weerasinghe, T.W., Au, E.Y.L. Foot arch charcterization, a review, a new metric and a comparison. Journal of the American Podiatric Medical Association, 100(1), 14-24, 2010.

[6] Williams, D.S., McClay, I.S. Measurements used to characterize the foot and the medial longitudinal arch: reliability and validity. Physical Therapy, 80(9), 864-71, 2000.

[7] Akhter, P. An anthropometric study of lower limb segment lengths measure-ments and their relationship with the stature and measurements of ultrasonographic fetal variables and their relationship with the maternal stature and determination of somatotype, footshape of Bangladeshi adult Muslim females [thesis]. Dhaka: Bangabandhu Sheikh Mujib Medical University; 2006.

[8] McPoil, G.T., Vicenzio, B., Cornwall, M.W., Collins, N. Can foot anthropometric measurements predict dynamic plantar surface contact area? Journal of Foot and Ankle Reearch ,2, 28, Oct 2009.

[9] Goonetileke, R.S., Ho, E.C.F., So, R.H.Y. Foot anthropometry in Hong Kong. in ASEAN 97 Conference,81-8, 1997.

[10] Kanaani, J.M., Mortazavi, S.B., Khavanin, A., Mirzai, R., Rasulzadeh, Y., Mansurizadeh, M. Foot anthropometry of 18-25 years old Iranian male students. Asian Journal of Scientific Research, 3(1), 62-9, 2010.

[11] Subotnick, S.I. The biomechanics of running: Implications for the prevention of foot injuries. Sports Medicine, 2(2), 144-53, 1985. 